\title{
Application of Pontryagin's Minimum Principle in Optimum Time of Missile Manoeuvring
}

\author{
Sari Cahyaningtias ${ }^{1}$,Subchan ${ }^{2}$ \\ ${ }^{1}$ Adi Buana University \\ ${ }^{2}$ Kalimantan Institute of Technology \\ Email: scahyaningtias@gmail.com,s.subchan@gmail.com
}

\begin{abstract}
Missile is a guided weapon and designed to protect outermost island from a thread of other country. It, commonly, is used as self defense. This research presented surface-to-surface missile in final dive manoeuvre for fixed target. Furthermore, it was proposed manoeuvring based on unmanned aerial vehicle (UAV), autopilot system, which needs accuration and minimum both time and thrust of missile while attacking object. This paper introduced pontryagin's Minimum Principle, which is useable to solve the problem. The numerical solution showed that trajectory of the missile is split it up in three sub-intervals; flight, climbing, and diving. The numerical simulation showed that the missile must climb in order to satisfy the final dive condition and the optimum time of a missile depend on initial condition of the altitude and the terminal velocity.
\end{abstract}

Keywords: missile, optimal control, pontryagin's minimum principle, thrust, angle of attack.

\section{INTRODUCTION}

Missile is a military rocket which has automatic control system to target an object and suit the direction. Missile is one of the unmanned aeral vehicle (UAV) which uses both in military and civilian needed such as controlling forest from illegal logging and sea from illegal fishing. It clearly is known that UAV can be handled using autopilot system to follow the references trajectory which could minimized both the risk and cost [1]

Trajectory tracking of surface-to-surface missile is divided in three sub-interval, namely: minimum altitude flight, climbing, and diving [2] [3]. Restrictiveness of fuel supply in maoeuvring can be handled by minimizing time manoeuvring to attack the target. Mathematics modelling of mass centre missile follow several assumption: the earth is spherical and non-rotation and ignoring lateral movement of the missile. Some boundary problems also were considered in this research such as massa of missile remains constant $\frac{d m}{d t} \cong 0$; there was no any obstacle while manoeuvring; The thrust and angle of attack are the controller of this problem which should be attacked fixed target.

Trajectory problem of missile has been studied by many researches both using classical control theory and modified optimal control. In 2013, Wang and Dong using hybrid algorithm to intercept trajectory optimization for multi-stage air defense missile which the missile always flies in the plane formed by the earth centre, launch point, and the predicted intercept point [4]. Maopeng at. al. In 2014, integrated missile guidance and control law using adaptive fuzzy sliding mode control. They also conducted stability of close loop system [5]. 
This paper presents computational result of the optimal trajectory of missile which minimized the time manoeuvring along the optimal trajectory. Furthermore, Vertical dive manoeuvre was chosen as final maneuvers by considering effect of its attacking. It would have shot to pieces the target permanently. Optimal control is applied by forcing the thrust and angle of attack to get optimum time using Pontryagin's Minimum Principle.

\section{METHODS}

Purpose of this research is to attack motionless target precisely and to minimize time manoeuvring. Here was given the definition of missile axes and angles.

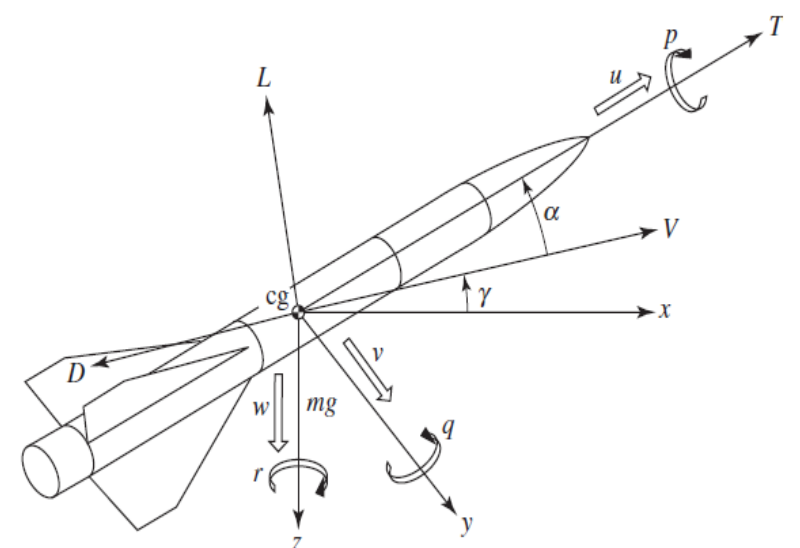

Figure 1 Definition of missile axes and angles

Based on Figure 1, The dynamic equations of a point mass missile, which may be written as [6]:

$$
\begin{aligned}
& \frac{d V}{d t}=\frac{1}{m}[T \cos \alpha-D]-g \sin \gamma \\
& \frac{d \gamma}{d t}=\frac{1}{m V}[L+T \sin \alpha]-\frac{g}{V} \cos \gamma \\
& \frac{d x}{d t}=V \cos \gamma \\
& \frac{d h}{d t}=V \sin \gamma
\end{aligned}
$$

There are four state variables, namely: speed $V, \gamma$ flight path angle, horizontal position $x$, and altitude $h$. The control variables are Thrust $T$ and angle of attack $\alpha$. Axial aerodynamics forces and normal aerodynamics forces are function of altitude, speed, and angle of attack, which are defined as:

$$
\begin{aligned}
& D(h, V, \alpha)=\frac{1}{2} C_{D} \rho V^{2} S \\
& C_{D}=A_{1} \alpha^{2}+A_{2} \alpha+A_{3}
\end{aligned}
$$

$$
\begin{aligned}
& L(h, V, \alpha)=\frac{1}{2} C_{L} \rho V^{2} S \\
& C_{L}=B_{1} \alpha+B_{2}
\end{aligned}
$$

where $\rho$, air density, is given by

$$
\rho=C_{1} h^{2}+C_{2} h+C_{3}
$$

whereas $\mathrm{S}$ reference area of missile, $m$ Massa and $g$ gravity.

Table 1. Physical Modelling Parameter

\begin{tabular}{|l|l|l|}
\hline Parameter & Nilai & Unit \\
\hline $\mathrm{M}$ & 1005 & $\mathrm{Kg}$ \\
\hline $\mathrm{G}$ & 9.81 & $\mathrm{~m} / \mathrm{s}^{2}$ \\
\hline $\mathrm{S}$ & 0.3376 & $\mathrm{~m}^{2}$ \\
\hline $\mathrm{A}_{1}$ & -1.9431 & \\
\hline $\mathrm{A}_{2}$ & -0.1499 & \\
\hline $\mathrm{A}_{3}$ & 0.2359 & \\
\hline $\mathrm{B}_{1}$ & 21.9 & \\
\hline $\mathrm{B}_{2}$ & 0 & \\
\hline $\mathrm{C}_{1}$ & $3.31210^{-9}$ & $\mathrm{Kg} \mathrm{m}^{-5}$ \\
\hline
\end{tabular}

\begin{tabular}{|l|l|l|}
\hline $\mathrm{C}_{2}$ & $-1.14210^{-4}$ & $\mathrm{Kg} \mathrm{m}^{-4}$ \\
\hline $\mathrm{C}_{3}$ & 1.224 & $\mathrm{Kg} \mathrm{m}^{-3}$ \\
\hline
\end{tabular}

Table 2. Boundary Condition and Constraints

\begin{tabular}{|c|c|c|}
\hline Parameter & Nilai & Unit \\
\hline $\mathrm{V}(0)$ & 210 & $\mathrm{~m} / \mathrm{s}^{2}$ \\
\hline$\gamma(0)$ & 0 & $\mathrm{Rad}$ \\
\hline$x(0)$ & 0 & $\mathrm{~m}$ \\
\hline$h(0)$ & $30,100,200$ & $\mathrm{~m}$ \\
\hline$V\left(t_{f}\right)$ & 290,310 & $\mathrm{~m} / \mathrm{s}^{2}$ \\
\hline
\end{tabular}




\begin{tabular}{|c|c|c|}
\hline$\gamma\left(t_{f}\right)$ & $-\frac{\pi}{2}$ & rad \\
\hline$x\left(t_{f}\right)$ & 10000 & meter \\
\hline
\end{tabular}

\begin{tabular}{|c|c|c|}
\hline$T_{\text {maks }}$ & 6000 & $\mathrm{~N}$ \\
\hline$T_{\min }$ & 1000 & $\mathrm{~N}$ \\
\hline
\end{tabular}

Boundary of control

$$
T_{\text {min }} \leq T \leq T_{\text {maks }}
$$

The problem of this research is how to get the minimum time of missile to attack the fixed target in vertical dive manoeuvre. Performance index of this problem is function of time which is given by:

$$
\mathrm{J}=\int_{\mathrm{t} 0}^{\mathrm{tf}} \mathrm{dt}
$$

where $t$ time of manoeuvring, $t_{0} \leq t \leq t_{f}$ in which $t_{0}$ initial time and $t_{f}$ final time.

\section{RESULTS AND DISCUSSION}

Mathematical analysis showed that some parts of those solution couldn't be gained using analytic method. That is why, computational analysis was applied in that case. This paper used optimal control Toolbox, namely Miser 3 which is developed by Jennings [8]

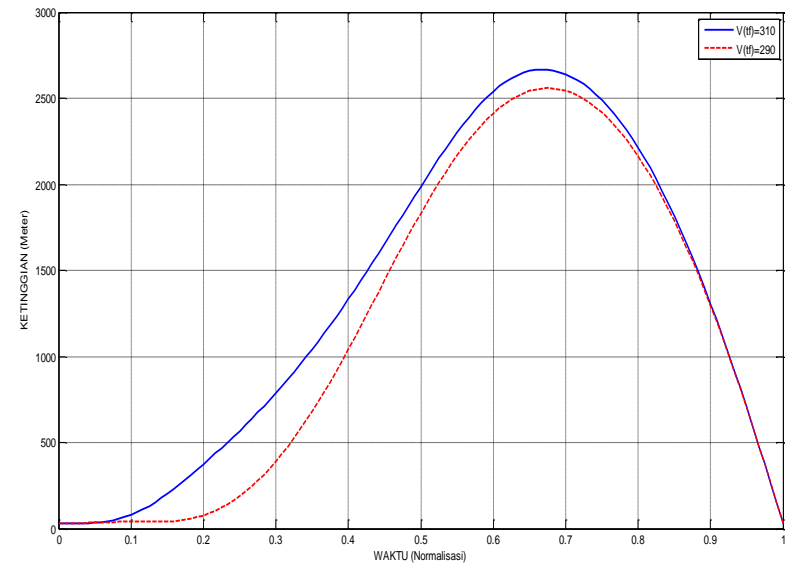

Figure 2 Performance of missile's altitude toward normalization time

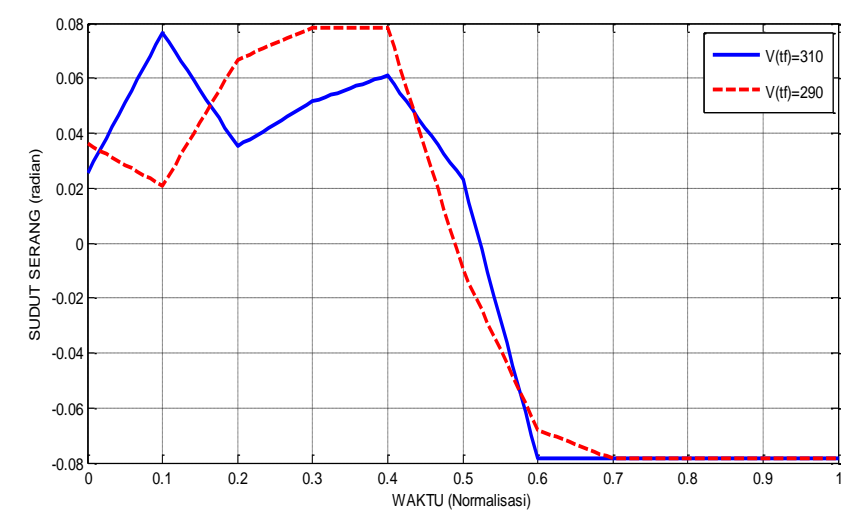

Figure 4 Performance of angle of attack missile toward time

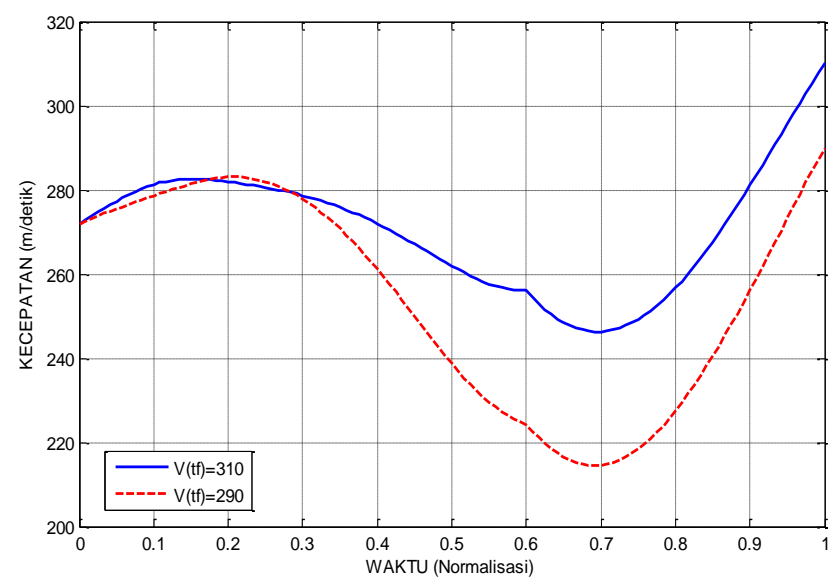

Figure 3 Performance of missile's velocity toward nirmalization time

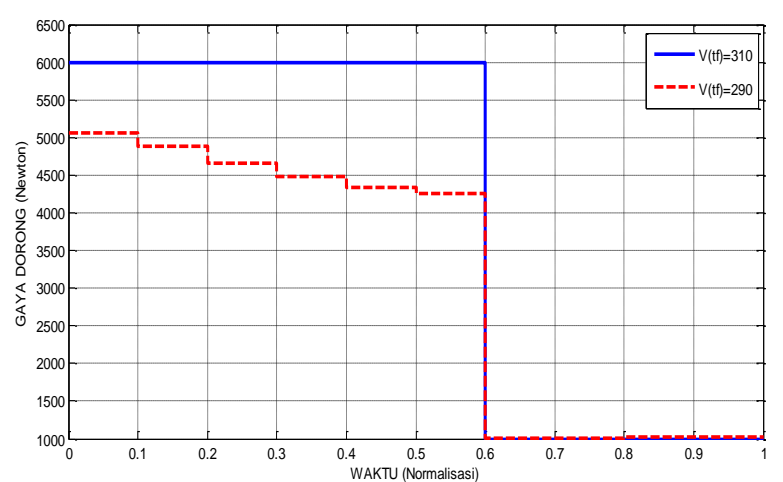

Figure 5 Performance of thrust of missile toward time

The trajectory of surface-to-surface missile with vertical dive manoeuvre is split of three subinterval: 
1. Minimum altitude flight

The missile launches at current altitude and therefore the altitude constraints are active directly at the start of the manoeuvre. In this case the speed of the missile remains constant on the minimum value $h$ min (see Figures 2 ) until the missile must start climbing while the thrust is on the maximum value. The flight time of first arc depends to the final-speed. Figure 5 shows that the thurst of missile remains at maximum, $6000 \mathrm{~N}$, while the speed slightly higher until the next sub-interval in Figure 3.

2. Climbing

The Speed of missile after flight in minimum altitude decreased gradually until reached the optimum altitude to start manoeuvre which is vertical dive manoeuvre. The thrust of missile remains maximum until time- 0.6 (normalization time), furthermore there suddenly switched into lowest boundary, $1000 \mathrm{~N}$. It showed that missile was turning down and starting dive manoeuvre.

3. Diving

The missile must gain the power to reach the target therefore the speed increase rapidly since the initial diving speed is lower than the final speed. The normal acceleration is saturated on the minimum value for this arc. Whereas the thrust remains constant around $1000 \mathrm{~N}$. The angle of attack convergenly is moving at -pi/40 radian.

Here presents computational solution of minimizing time problem depends on initial altitude and final speed.

Table 3. Optimum time by computation

\begin{tabular}{|c|c|c|}
\hline $\begin{array}{c}\text { Initial Altitude } \\
\text { (meter) }\end{array}$ & $\begin{array}{c}\text { Final Speed } \\
(\mathrm{m} / \mathrm{s})\end{array}$ & Objective Function (s) \\
\hline 30 & 290 & 48.0781385 \\
\hline \multirow{2}{*}{100} & 310 & 44.8815557 \\
\hline \multirow{2}{*}{200} & 290 & 47.9329181 \\
\cline { 2 - 3 } & 310 & 44.8199641 \\
\cline { 2 - 3 } & 290 & 47.7656314 \\
\hline
\end{tabular}

\section{CONCLUSION}

In this paper, analysis of surface-to-surface missile which considered objective and dynamical system showed that trajectory tracking of this missile was split up in three subintervals, namely flying, climbing, and diving in which had different performances of speed. Those paths were result by controlling thrust and angle of attack. First path, the missile launched at $\mathrm{h}=30 \mathrm{~m}$ and remained stable in this altitude. Second part, velocity of missile decreased dramatically while climbing to reach optimum altitude before manoeuvring. Furthermore the last path, dive manoeuvring, the speed of missile got faster rapidly to final speed. It would be happened while missile was at 30 meters above the target with angle of attack's - 90 deg. Travel time of missile was influenced by starting position while it was shoot and final speed of missile itself. The higher launch site and the bigger final speed of missile affected the shorter its time travel. Another variable that should be considered in missile manoeuvring is energy. It can be minimize in objective function. This problem can be conducted in future reserach. 


\section{REFERENCES}

[1] S. Subchan, "Pythagorean Hodograph Path Planning for Tracking Airborne Contaminant using Sensor Swarn," in International Instrumentation and Measurement Technology Conference Victoria, Canada, 2008.

[2] S. Subchan, "Trajectory happing of Surface-to-Surface Missile with Terminal Impact Angle Constraint," Makara Teknologi Indonesia University, pp. 65-70, 2007.

[3] S. Subchan and R. Zbikowski, Computational Optimal Control: Tools and Practice, UK: John Wiley and Sons Ltd, 2009.

[4] F. B. Wang and C. H. Dong, "Fast Intercept Trajectory Optimization for Multi-Stage Air Defense Missile using Hybrid Algorthm," Elsivier Procedia engineering, pp. 447-456, 2013.

[5] e. a. Maoping, "Backstepping Design of Missile Guidance and Control Based on Adaptive Fuzzy Sliding Mode Control," Chinese Journal of Aeronautics, pp. 634-642, 2014.

[6] G. Siouris, Missile Guidance and Control Systems, USA: Springer, 2003.

[7] D. S. Naidu, Optimal Control Systems, USA: CRC Press LLC, 2002.

[8] L. S. Jennings, M. E. Fisher, K. L. Teo and C. J. Goh, Miser3 Optimal Control Software, Australia: The University Of Western Australia, 2002. 